\title{
Международная защита прав вынужденных мигрантов в решениях Европейского суда по правам человека (Часть 1)*
}

Иванов Д.В. ${ }^{* *}$

В статье анализируется роль Европейского суда по правам человека в международной защите прав вынужденных мигрантов, подробно рассматривается судебная практика Суда в отношении различных прав и свобод, закрепленных в Европейской конвенции о защите прав человека и основных свобод (1950) и протоколах к ней.

В первой части статьи особое внимание уделяется практике рассмотрения ЕСПЧ дел о депортации или экстрадиции, в том числе, с участием Российской Федерации.

Ключевые слова: права человека; Европейский суд по правам человека; Европейская конвенция о защите прав человека и основных свобод; права беженцев; депортация; экстрадиция.

Европейская конвенция о защите прав человека и основных свобод 1950 года (далее по тексту - ЕКПЧ) была принята для защиты ограниченного круга прав и свобод человека, в который не входили права беженцев, лиц ищущих убежище, и иных категорий вынужденных мигрантов в том виде, в каком они предусмотрены в Конвенции о статусе беженцев 1951 года. Вместе с тем, как отмечается некоторыми авторами, в статье 1 ЕКПЧ предусматривается, что права и свободы, определенные в разделе 1 Конвенции, гарантируются каждому лицу, находящемуся под юрисдикцией государства-участника, то есть независимо от гражданства или статуса пребывания на территории этой страны. Таким образом, Конвенция распространяет свое действие и гарантирует предусмотренные в ней права всем вышеуказанным лицам, в том числе и беженцам и определенным категориям вынужденных мигрантов ${ }^{1}$.

В российской и зарубежной доктрине международного права предложена определенная классификация прав беженцев применительно

\footnotetext{
* Доклад на международной научной конференции «Актуальные теоретические вопросы современного международного права», 3 октября 2013 г., МГИМО (У) МИД России. ** Иванов Дмитрий Владимирович - к.ю.н., доцент, профессор кафедры международного права МГИМО (У) МИД России. prof.ivanovdv@gmail.com.
} 
к ЕКПЧ. Во-первых, права, необходимые для защиты беженцев от высылки. Во-вторых, права, необходимые для защиты основных прав беженцев, находящихся на территории договаривающихся государств. В деле Чэхал против Соединенного Королевства (Chahal v. UK²) Европейский суд по правам человека (далее по тексту - ЕСПЧ) постановил, что защита от высылки согласно статье 3 ЕКПЧ шире, чем согласно Конвенции о статусе беженцев, поскольку статья 3 предусматривает абсолютные и безусловные гарантии в отношении высылки и может быть использована даже лицами, подозреваемыми в терроризме 3 .

В любом случае, часть статей ЕКПЧ и протоколов к ней касается отдельных аспектов миграции, регулируя их прямо или косвенно. Непосредственно вышеуказанные международно-правовые акты регулируют следующие вопросы: 1) законное задержание или заключение под стражу лица с целью предотвращения его незаконного въезда в страну или лица, против которого предпринимаются меры по его высылке или выдаче; 2) право на свободу передвижения и свободу выбора местожительства; 3) запрет высылки с территории государства, гражданином которого является заявитель, и право на возвращение в государство гражданской принадлежности; 4) запрет коллективной высылки иностранцев; 5) гарантии при осуществлении процедуры высылки иностранцев, законно пребывающих на территории государства.

Для того чтобы определить участие ЕСПЧ в международной защите прав вынужденных мигрантов, следует более подробно рассмотреть судебную практику ЕСПЧ в отношении различных прав и свобод, закрепленных в ЕКПЧ и протоколах к ней.

В статье 5 ЕКПЧ закреплено право каждого на свободу и личную неприкосновенность «1. Каждый имеет право на свободу и личную неприкосновенность. Никто не может быть лишен свободы иначе как в следующих случаях и в порядке, установленном законом: ...

f) законное задержание или заключение под стражу лица с целью предотвращения его незаконного въезда в страну или лица, против которого предпринимаются меры по его высылке или выдаче.

4. Каждый, кто лишен свободы в результате ареста или заключения под стражу, имеет право на безотлагательное рассмотрение судом правомерности его заключения под стражу и на освобождение, если его заключение под стражу признано судом незаконным. 
5. Каждый, кто стал жертвой ареста или заключения под стражу в нарушение положений настоящей статьи, имеет право на компенсацию».

Согласно судебной практике ЕСПЧ правила, установленные статьей $5 \S 1(\mathrm{f})$, немного отличаются от положений статьи $5 \S 1$ (c). В частности, статья 5 § 1 (f) не требует, чтобы содержание под стражей лица, в отношении которого осуществляется депортация, считалось необходимым с разумной точки зрения, например, чтобы предотвратить совершение им преступления или его побег. Для соблюдения статьи 5 § 1 (c) важны причины, по которым судья избирает меру пресечения в виде лишения свободы, которые он указывает в соответствующем решении. Последний должен их подробно описать в своем постановлении о заключении под стражу. В отличие от данных положений статья 5 § 1 (f) требует, только чтобы соответствующие действия осуществлялись в рамках процедуры депортации. Проверка, осуществляемая ЕСПЧ, ограничена установлением существования законного основания для содержания под стражей и злоупотреблений при вынесении решения о заключении лица под стражу.

Лишение свободы согласно статье $5 \S 1$ (f) будет оправдано, пока осуществляется процедура депортации. Если данная процедура не завершена должным образом, заключение под стражу неправомерно.

Термин «законность» при этом означает не только обязанность соблюдать нормы национального материального и процессуального права; «законность» также означает требование, чтобы любое лишение свободы соответствовало цели статьи 5 ЕКПЧ.

При рассмотрении дела о депортации или экстрадиции ЕСПЧ должен установить, соответствует ли само национальное законодательство государства - участника ЕКПЧ положениям Конвенции, включая ее общие принципы, непосредственно закрепленные в ней либо вытекающие из нее. Относительно данного вопроса ЕСПЧ полагает, что когда речь идет о лишении свободы, особенно важно соблюдение общего принципа правовой определенности. Закрепляя, что любое лишение свободы должно осуществляться «в порядке, установленном законом», статья $5 \S 1$ не просто отсылает к национальному законодательству. Как и выражение «предусмотрено законом» во втором абзаце статей 8-11, положение статьи $5 \S 1$ относится к понятию «качества закона» и требует соответствия принципу верховенства закона, который является неотъемлемым для всех статей Конвенции. «Качество закона» в этом 
смысле подразумевает, что в том случае, когда национальное законодательство санкционирует лишение свободы, оно должно быть достаточно доступным, точным и предсказуемым в применении, с тем чтобы была исключена малейшая возможность произвола ${ }^{4}$.

Данные основополагающие принципы были утверждены в ранних делах ЕСПЧ, таких, как Чахал против Соединенного Королевства, Гонзалес против Испании ${ }^{5}$ и подтверждались в последующем.

Содержание под стражей в соответствии со статьей 5 § 1 (f) должно обеспечиваться определенными процедурными гарантиями, необходимыми для того, чтобы исключить риск произвола. В деле Чахал против Соединенного Королевства ЕСПЧ посчитал, что пересмотр вопроса по содержанию под стражей миграционного консультационного совета в связи с необходимостью обеспечения национальной безопасности, предполагает некоторые гарантии в отношении произвольного заключения под стражу, но, тем не менее, он пришел к выводу, что данная процедура не была достаточной для того, чтобы соблюсти требования статьи 5 (4) ЕКПЧ 6.

Процедурные гарантии, как видно, связаны в большой степени с пунктом 4 статьи 5 ЕКПЧ. Согласно ЕКПЧ в интерпретации ЕСПЧ лицо, заключенное под стражу, должно иметь доступ к суду и возможность заявить о своей позиции лично или через представителя. В деле Аль-Нашиф против Болгарии ${ }^{7}$ ЕСПЧ столкнулся с ситуацией, когда в законодательстве Болгарии не предусматривалась возможность судебного обжалования в отношении содержания под стражей, в случае если решение о депортации было принято в связи с необходимостью обеспечения национальной безопасности. В результате попытки одного из заявителей по судебному обжалованию законности его заключения под стражу оказались безуспешными. Кроме того, заявитель находился в изоляции, без связи с внешним миром; ему было отказано в общении с адвокатом. ЕСПЧ признал в данном деле, что ситуация, при которой отсутствует возможность судебного контроля над решением о депортации, нарушает статью 5 § 4 ЕКПЧ (§92-94).

Даже если в решении о депортации имеются какие-то недостатки, это может и не повлиять на законность такого решения по смыслу статьи 5 § 1 (f), особенно когда такие недостатки быстро выявляются и устраняются, а задержанный отпускается на волю, как в деле Сливенко против Латвии ${ }^{8}$. 
В деле М. и другие против Болгарии ${ }^{9}$ ЕСПЧ отметил в отношении соблюдения пункта 1 статьи 5 Конвенции, что лишение свободы может быть оправданным в соответствии с Конвенцией, пока продолжается процедура высылки или выдачи. Если такое разбирательство не проводится с надлежащей старательностью, содержание под стражей перестает быть допустимым. Первый заявитель содержался под стражей в течение двух лет и восьми с половиной месяцев. Хотя решение о его высылке было принято в декабре 2005 года, власти не делали попыток получения необходимых документов до февраля 2007 года, когда было направлено письмо в посольство. Не получив ответа, они направили повторное требование в сентябре 2008 года, через год и семь месяцев. Кроме того, государство-ответчик не представило доказательств принятия мер по обеспечению принятия первого заявителя третьей страной. Соответственно, основания для содержания первого заявителя под стражей с целью высылки не сохранялись в течение всего периода его заключения, поскольку власти не действовали с надлежащей старательностью. Кроме того, хотя лишение свободы первого заявителя было основано на действительном правовом акте, наличие двух самостоятельных постановлений о его содержании под стражей, выданных двумя различными органами, представлялось источником неопределенности, и правовое значение существования двух постановлений являлось неясным. Кроме того, даже после июня 2009 года, когда решение об отмене одного из этих постановлений вступило в силу, полиция продолжала ссылаться на него, как если бы оно являлось действительным, в пренебрежение окончательным решением национального суда.

Поскольку ЕСПЧ уже выносил аналогичные постановления против Болгарии, и на рассмотрении находятся иные сходные дела, он нашел необходимым оказать государству-ответчику содействие в соблюдении его обязанности по исполнению постановления Европейского Суда. В частности, ЕСПЧ выразил мнение о том, что меры общего характера по исполнению данного постановления должны включать изменения в закон об иностранцах или иное законодательство Болгарии, обеспечивающие чтобы: (i) даже если в качестве основания для высылки указываются мотивы национальной безопасности, фактическая основа и мотивы принятия решения подлежали тщательной судебной проверке, при необходимости с принятием необходимых процессуальных мер, относящихся к использованию секретной информации; (ii) суды, рассматривающие жалобы о высылке, сопоставляли цель, 
преследуемую постановлением о высылке, с фундаментальными правами человека заинтересованных лиц, включая право на уважение их семейной жизни; (iii) страна назначения всегда указывалась в правовом акте, и изменение страны назначения подлежало обжалованию; (iv) ссылки на угрозы гибели или жестокого обращения в стране назначения внимательно рассматривались судами; и (v) такие ссылки в жалобах о высылке имели автоматическое приостанавливающее действие на время их рассмотрения.

Что касается места задержания и содержания под стражей, то ЕСПЧ сталкивался не только с анализом обоснованности содержания в специальных центрах размещения, но и с такими нестандартными ситуациями, как пребывание в транзитной зоне аэропорта.

В деле Амур против Франции речь шла о гражданах Сомали, которые прибыли из Сирии во Францию и были задержаны в международной, транзитной зоне аэропорта Орли в Париже. В течение нескольких недель они находились в этой транзитной зоне без доступа к ним адвокатов. Они не имели возможности подать заявление о предоставлении убежища, поскольку среди прочего французское правительство утверждало, что эти люди не находятся на территории Франции, поскольку формально не пересекли границу. Соответственно, нахождение в транзитной зоне никоим образом не нарушает их прав, поэтому на них не распространяются положения статьи 5 (порядок и процедурные гарантии при лишении свободы). Суд возразил на это, указав, что хотя часть 1 (f) статьи 5 предполагает возможность законного задержания лиц с целью предотвращения нелегального въезда (или задержания лиц, в отношении которых принято решение о высылке или выдаче), но в данном случае такое задержание незаконно, так как оно регулировалось не французскими законами, а всего лишь подзаконным актом - инструкцией. Более того, французское правительство утверждало, что это вообще не задержание, так как эти люди всегда имели возможность согласиться на депортацию в Сирию, откуда они прибыли. Таким образом, никакого лишения свободы по смыслу статьи 5 не было, а было их как бы добровольное решение о том, что они хотят оставаться в аэропорту вместо того, чтобы вернуться в Сирию и быть свободными. Эту интерпретацию суд также целиком отклонил, так как было очевидно, что возвращение в Сирию на практике было для них весьма проблематичным, Сирия, по их утверждению, не являлась для них безопасной третьей страной. Фактически они просили убежище 
во Франции, и Франция обязана была рассмотреть их заявления. Кроме того, сама по себе процедура задержания без возможности получения юридической помощи, не предусмотренной на тот момент во французском законодательстве, без возможности обжалования, была признана судом нарушением. Суд отметил, в случае, если национальное законодательство дозволяет лишение свободы, особенно в отношении иностранцев, ищущих убежище, оно должно быть особенно доступным и четким, с тем, чтобы исключить возможность его произвольного применения. Эти характеристики имеют особое значение в отношении лиц, ищущих убежище, находящихся в аэропортах ${ }^{10}$.

В деле Нолан против России ${ }^{11}$ заявитель, иностранец, проживавший в России, но вылетевший на Кипр, был задержан и удерживался в транзитной зоне аэропорта. После прохождения пограничного контроля, ему отказали во въезде на российскую территорию и провели в транзитный зал. В транзитном зале его заперли на ночь в маленькой комнате. Ему разрешили пользоваться туалетом, баром и телефоном утром следующего дня. Затем он купил билет в Таллинн и сел на самолет. Сотрудник Пограничной службы сопровождал его до того момента, пока он не сел в самолет.

Несмотря на то, что заявитель не пересек российскую границу, как указало Правительство РФ, во время его нахождения в транзитном зале, он был под юрисдикцией Российской Федерации. Правительство РФ не заявляло о том, что транзитная зона аэропорта Шереметьево имела экстратерриториальный статус или другим образом находилось вне контроля государства (сравните Shamsa v. Poland, nos. 45355/99 and 45357/99, § 45, 27 November 2003). Суд установил, что заявитель находился под юрисдикцией Российской Федерации.

Тот факт, что заявитель не подвергался процедуре уголовного или административного задержания, не имеет значения для оценки Суда в отношении наличия de facto лишения или ограничения свободы. В отношении данной конкретной ситуации, ЕСПЧ отметил, что вовремя ночного пребывания в аэропорту Шереметьево покинуть комнату, в которую был помещен, по своему желанию он не мог, поскольку она была заперта снаружи. Несмотря на то, что ему было позволено пользоваться туалетом и баром на следующее утро, он мог делать это только под наблюдением офицера пограничной службы. Фактически, его отъезд был возможен на следующий день только потому, что он купил билет в Эстонию, к моменту чего его ночное заключение уже имело место. 
Заявление Заявителя о том, что его свобода на ночь была ограничена, подтверждается требованиями Инструкции о пересечении границы, которая обязывала пограничный контроль сопровождать лиц, находящихся в ситуации Заявителя, в «изолированном пространстве» и помещать их «под охрану» до того, как они покинут территорию России. Поэтому нахождение заявителя ночью в транзитном зале аэропорта Шереметьево в Москве было эквивалентно на практике, исходя из тех ограничений, которые он испытывал, лишению свободы, ответственными за которое были российские власти.

Поскольку Правительство РФ указало, что заявителя не «задержали» согласно значению российского права, они не ссылались на национальные правовые акты, предусматривающие ограничение свободы, которому он был подвергнут. Суд постановил, что Инструкция о пересечении границы не соответствовала требованиям доступности и предсказуемости, а также не соответствовала стандартам «качества права», предусмотренным ЕКПЧ. Национальная система не смогла защитить Заявителя от произвольного лишения свободы, и его задержание не могло рассматриваться как «предусмотренное законом», исходя из целей статьи $5 \S 1$ Конвенции ${ }^{12}$.

В деле Конка против Бельгии ${ }^{13}$ полиция прибегла к хитрости, чтобы заманить заявителей в полицейский участок и депортировать их. Она направила им уведомление о необходимости явиться в полицию для заполнения заявлений о предоставлении статуса беженца. По прибытии заявителям было вручено решение о депортации, и они были задержаны. Хотя Суд не может исключить правомерности ситуации, когда полиция использует хитрость, в частности, чтобы войти в доверие к лицам, ищущим убежища, с целью их задержания и последующей депортации, такие действия могут быть признаны нарушающими общие принципы, предусмотренные прямо или косвенно в Конвенции. В рассматриваемом деле полиция осознано прибегла к вышеуказанному уведомлению, содержащему ложные сведения, чтобы привлечь как можно большее число возможных нарушителей.

Суд напомнил, что перечень исключений в отношении права на свободу является исчерпывающим и только узкое толкование данных ограничений соответствует цели статьи 5 ЕКПЧ. Данное требование также должно соблюдаться в ходе процедуры уведомления, вне зависимости оттого, находятся ли получатели уведомлений в стране на законных основаниях или нет. ЕСПЧ заключил, что, даже, хотя речь и идет 
об иностранцах, нарушивших режим нахождения на территории страны, осознанное решение властей упростить и повысить эффективность запланированной операции для высылки иностранцев, введя их в заблуждение по поводу цели уведомления, чтобы упростить их арест, противоречит статье 5.

Интересная ситуация складывается, когда в отношении заявителя суд государства происхождения выносит решение о заключении его под стражу, а в другом государстве он арестовывается и заключается под стражу. Возникает вопрос: каким образом должно оформляться его заключение под стражу, чтобы оно соответствовало положениям ЕКПЧ?

В деле Джураев против России ${ }^{14}$ ЕСПЧ признал нарушение статьи $5 \S 1$ (f). Суд отметил, что первоначальное заключение заявителя под стражу было санкционировано 29 января 2007 года межрайонной прокуратурой на основании положений Минской конвенции о правовой помощи и правовых отношениях по гражданским, семейным и уголовным делам от 22 января 1993 года. Хотя Постановление от 29 января 2007 года не содержало ссылки на соответствующие положения УПК (часть 2 статьи 466: если к запросу о выдаче лица прилагается решение судебного органа иностранного государства о заключении лица под стражу, то прокурор вправе подвергнуть это лицо домашнему аресту или заключить его под стражу без подтверждения указанного решения судом Российской Федерации), предусмотренное национальным законодательством право прокурора решать вопрос о заключении заявителя под стражу в отсутствие решения российского суда может вытекать из этого положения.

ЕСПЧ подчеркнул, что ни статья 61 Минской конвенции, ни часть 2 статьи 466 УПК РФ не устанавливают правил относительно порядка избрания меры пресечения в отношении лица, о выдаче которого поступил запрос, или каких-либо сроков для его содержания под стражей в ожидании выдачи.

К моменту заключения заявителя под стражу Конституционный Суд России уже разъяснил, что в разбирательстве о выдаче право на свободу обеспечивается теми же гарантиями, что и в других видах уголовного разбирательства. Он недвусмысленно указал, что применение мер пресечения в ожидании выдачи должно регулироваться не только статьей 466 УПК РФ, но также нормами о мерах пресечения, содержащимися в главе 13 УПК РФ. 
Кроме того, власти Российской Федерации подтвердили, что содержание заявителя под стражей в ожидании выдачи регулировалось, в частности, главой 13 УПК РФ.

При таких обстоятельствах ЕСПЧ заключил, что для того чтобы быть «законным» в значении подпункта «f» пункта 1 статьи 5 Конвенции, содержание заявителя под стражей не должно противоречить не только требованиям части 2 статьи 466 УПК РФ, но также положениям, регулирующим применение меры пресечения в виде заключения под стражу, а именно статьям 108 и 109, включенным в главу 13 УПК РФ.

Часть 4 статьи 108 УПК РФ прямо указывает, что вопрос о заключении под стражу решается судьей районного суда в присутствии заинтересованного лица. Из формулировки пункта 48 статьи 5 и части 2 статьи 31 УПК РФ следует, что районный суд является судом, уполномоченным действовать на основании Уголовно-процессуального кодекса России, что подразумевает, что термин «районный суд» означает суд, учрежденный и действующий в соответствии с российским законодательством. Соответственно, судья районного суда является должностным лицом, уполномоченным осуществлять правосудие на территории Российской Федерации. Формулировка части 4 статьи 108 УПК не дает оснований полагать, что иностранный суд может подменять российский районный суд при разрешении вопроса о помещении лица под стражу. Соответственно, тот факт, что помещение заявителя под стражу не было санкционировано российским судом, явно противоречит части 4 статьи 108 УПК.

Кроме того, даже если предположить, что первоначальное заключение заявителя под стражу совместимо с положениями национального законодательства, оно должно было утратить «законность» после истечения двухмесячного периода, предусмотренного частью 1 статьи 109 УПК. Часть 2 статьи 109 УПК недвусмысленно указывает, что по истечении двухмесячного срока содержание под стражей может быть продлено до шести месяцев только по решению судьи районного суда или военного суда соответствующего уровня. В отсутствие решения российского суда о продлении срока содержания заявителя под стражей ЕСПЧ вынужден был заключить, что после 27 марта 2007 года, то есть по истечении двух месяцев после даты его заключения под стражу, заявитель содержался под стражей в нарушение национального законодательства. 
В том же деле возник вопрос о возможности для заявителя обжаловать решение о его заключении под стражу. Во время содержания под стражей лицу должно быть предоставлено средство правовой защиты, позволяющее добиться безотлагательного судебного рассмотрения вопроса о правомерности содержания под стражей. Такая проверка должна при необходимости обеспечить освобождение лица из-под стражи. Наличие средства правовой защиты, предусмотренного пунктом 4 статьи 5 ЕКПЧ, должно быть достаточно определенным не только в теории, но и на практике, поскольку в отсутствие этого качества средство правовой защиты не будет отвечать требованиям доступности и эффективности, предъявляемым в целях указанного положения. Заявитель содержался под стражей в ожидании выдачи на основании двух решений межрайонной прокуратуры. Ни одно из решений не содержало указаний на возможность их обжалования. Минская конвенция не содержит правил о порядке обжалования решения о заключении под стражу в процессе выдачи, предусмотренной статьями 60 и 61. Соответственно, заявитель не располагал средствами правовой защиты, вытекающими из этой конвенции, которые позволяли бы оспаривать законность его содержания под стражей в ожидании выдачи. ЕСПЧ отметил, что очевидно отсутствие у заявителя способа оспорить законность выданного узбекским судом ордера на арест в российском суде, и, таким образом, он не мог добиться судебной проверки законности его содержания под стражей на основе этого ордера.

Что касается ссылки властей Российской Федерации на главу 13 УПК, ЕСПЧ подчеркнул, что единственное положение этой главы, регулирующее обжалование законности содержания под стражей, предусматривает, что решение суда о заключении под стражу может быть обжаловано в вышестоящий суд. Глава 13 обходит молчанием вопрос о заключении под стражу, санкционированном прокурором, а не судом. Соответственно, заявитель не мог обжаловать в суд соответствующие решения межрайонной прокуратуры, в соответствии с положениями главы 13 УПК, на которые ссылались власти Российской Федерации.

Что касается утверждения властей Российской Федерации о том, что заявитель мог обжаловать незаконность его содержания под стражей прокурору или в суд на основании статей 124 и 125 УПК, ЕСПЧ отметил, что глава 16 УПК предусматривает возможность обжалования «участниками уголовного судопроизводства» решений, принятых в ходе предварительного следствия, таких как отказ в возбуждении 
уголовного дела или решение о его прекращении. Отсутствуют данные о том, что заявитель являлся «участником уголовного судопроизводства» в значении, придаваемом этой формулировке российскими судами.

В итоге ЕСПЧ признал нарушение, поскольку в России отсутствовали эффективные средства правовой защиты, которые заявитель мог бы использовать для проверки законности своего содержания под стражей.

В деле Абдулхаков против России ${ }^{15}$ ЕСПЧ отметил, что в российском законодательстве не содержится каких-либо особых положений, устанавливающих процедуру помещения под стражу в ожидании получения запроса об экстрадиции. В данном деле прокурор ссылался статью 161 Минской конвенции 1993 г. и статью 108 УПК РФ, которая регулирует содержание под стражей в ходе уголовного процесса. ЕСПЧ еще раз повторил, что Статья 108 УПК РФ не может служить достаточным законным основанием для решения прокурора о заключении лица под стражу по той причине, что в отношении него было вынесено решение об аресте иностранным судом, как в деле Джураев против России.

После получения запроса о выдаче содержание лица под стражей начинает регулироваться положениями УПК РФ об избрании или применении избранной меры пресечения для обеспечения возможной выдачи лица, которые не предусматривают никакой процедуры по установлению или продлению содержания под стражей, а также не определяют никакие временные ограничения заключения под стражей в ходе процедуры выдачи.

ЕСПЧ отметил отсутствие каких-либо четких положений национального законодательства РФ, определяющих условия, сроки содержания под стражей в описываемой ситуации и прокурором какого уровня должен решаться данный вопрос после получения запроса о выдаче.

Статья 2 Протокола № 4 к ЕКПЧ регулирует свободу передвижения, предусматривая, что «1. Каждый, кто на законных основаниях находится на территории какого-либо государства, имеет в пределах этой территории право на свободу передвижения и свободу выбора местожительства.

2. Каждый свободен покидать любую страну, включая свою собственную.

3. Пользование этими правами не подлежит никаким ограничениям, кроме тех, которые предусмотрены законом и необходмы 
в демократическом обществе в интересах национальной безопасности или общественного спокойствия, для поддержания общественного порядка, предотвращения преступлений, охраны здоровья или нравственности или для защиты прав и свобод других лищ.

4. Права, признанные в пункте 1, могут также, в определенных районах, подлежать ограничениям, вводимым в соответствии с законом и обоснованным общественными интересами в демократическом обществе».

Согласно принципам, установленным ЕСПЧ в случае рассмотрения индивидуальных жалоб в задачу Суда не входит пересмотр национального законодательства или практики. Суд лишь должен, насколько это возможно, не пренебрегая общим контекстом, обратиться к проблемам, поднятым в соответствующем деле ${ }^{16}$.

Рассматриваемая нами норма Протокола №4 к ЕКПЧ защищает свободу передвижения лиц «законно находящихся на территории Государства». Данное положение касается национального законодательства государств. Именно в задачи национального законодательства и государственных органов входит определение условий, которые должно соблюдать лицо, чтобы его пребывание в государстве рассматривалось как «законное». Статья 2 Протокола № 4 не может толковаться, как предоставляющая иностранному лицу право проживать или оставаться в стране, гражданином которой оно не является, и она не касается условий, на которых лицо вправе оставаться в стране.

Так, иностранцы, временно допущенные в определенный округ или на определенную территорию государства, в ходе процедуры по определению их права на получение вида на жительство согласно определенным положениям закона, могут считаться «законно» присутствующими на территории, пока они соблюдают условия их допуска и пребывания ${ }^{17}$.

В деле Омвениеке против Германии ${ }^{18}$ заявитель жаловался, что обязательство лиц, ищущих убежища, согласно Закону о процедуре предоставления убежища, оставаться в пределах определенного округа и его осуждение за нарушение данного обязательства нарушили его право на свободу передвижения. ЕСПЧ установил, что с момента его въезда в Германию заявитель имел разрешение на временное пребывание, согласно которому ему разрешалось пребывание в определенном городе в соответствии с национальным законодательством. 
В таких делах, как это, несмотря на то, что согласно общему правилу ЕСПЧ не является четвертой инстанцией для национальных судов и не анализирует их решения с точки зрения надзорной инстанции, все же он вынужден принимать во внимание их выводы, оценивая их на предмет наличия произвола и явной несправедливости. В рассматриваемом деле Суд проанализировал решения национальных судов по делу, в которых не нашел никаких проявлений произвола, и заключил, что нахождение заявителя на территории Германии не может быть «законным».

При разработке Протокола стороны учли, что его положения достаточно близки по своему содержанию к Статье 8 ЕКПЧ, где речь идет о частной жизни. Этим объясняется схожесть положений о возможных ограничениях прав, закрепленных в данных статьях.

\begin{tabular}{|l|l|}
\hline \multicolumn{1}{|c|}{ Ограничения по Статье 8 ЕКПЧ } & \multicolumn{1}{c|}{\begin{tabular}{c}
\multicolumn{1}{c|}{ Ограничения по Статье 2 Протокола №4 } \\
к ЕКПЧ
\end{tabular}} \\
\hline национальная безопасность & национальная безопасность \\
\hline общественный порядок & общественный порядок \\
\hline - & общественное спокойствие (ordre public) \\
\hline $\begin{array}{l}\text { экономическое благосостояние } \\
\text { страны }\end{array}$ & - \\
\hline $\begin{array}{l}\text { предотвращение беспорядков или } \\
\text { преступлений }\end{array}$ & предотвращение преступлений \\
\hline охрана здоровья или нравственности & охрана здоровья или нравственности \\
\hline защита прав и свобод других лиц & защиты прав и свобод других лиц \\
\hline
\end{tabular}

Как мы видим, основания на ограничение государством права на частную жизнь схожи с основаниями ограничения, установленными статьей 2 Протокола №4. Можно выделить только два отличия: общественное спокойствие и экономическое благосостояние. Кроме того, согласно пункту 4 рассматриваемой статьи указанные права могут также, в определенных районах, подлежать ограничениям, вводимым в соответствии с законом и обоснованным общественными интересами в демократическом обществе.

Понятие «ordre public» понимается в самом широком смысле, оно включает состояние безопасности, спокойствия, мира в обществе. В ходе разработки Протокола также предлагалось включить такое ограничение, как экономическое благополучие страны (economic welfare), 
однако оно было отвергнуто. Некоторые представители участников рабочей группы заявили, что в их странах подобного рода ограничения запрещены. Кроме того, предоставление возможности установления таких ограничений могло бы привести к различным злоупотреблениям ${ }^{19}$.

Статья 3 Протокола №4 к ЕКПЧ регулирует запрещение высылки граждан, предусматривая, что «1. Никто не может быть выслан путем индивидуальных или коллективных мер с территории государства, гражданином которого он является. 2. Никто не может быть лишен права на въезд на территорию государства, гражданином которого он является».

При разработке Протокола было решено, что его текст должен содержать запрет, адресованный любым конституционным, законодательным, административным или судебным органам, высылать собственных граждан из страны гражданской принадлежности. При этом рассматривалась возможность использования одного из двух терминов для обозначения высылки гражданина за пределы государства его гражданства: exile и expel. По мнению большинства экспертов, термин «ехіlе» не следовало использовать, поскольку он слишком широкий и может по-разному интерпретироваться. В результате была достигнута договоренность, что речь идет именно о высылке («еxpulsion»), которая с технической точки зрения применяется только к иностранцам. Следует иметь в виду, что положения данного пункта не распространяются на экстрадицию.

Заявитель не вправе ссылаться на нарушение данного пункта, если он желает избежать определенных обязательств, которые не противоречат ЕКПЧ, например, обязательств, касающихся военной службы.

Что если государство лишит человека гражданства с целью его высылки? Будет ли в таком случае нарушено право, закрепленное в рассматриваемой статье? На этот вопрос нам дает ответ Пояснительный доклад к Протоколу №4: данная проблема не покрывается Протоколом. Большинство экспертов решили, что Статья 3 не должна затрагивать такой деликатный вопрос, как легитимность лишения человека гражданства. Кроме того, было бы трудно доказать в такой ситуации, что лишение гражданства было осуществлено с намерением выслать соответствующее лицо.

Одним из интересных прецедентов, касающимся нарушений статьи 3 Протокола №4, является дело Сливенко против Латвии, где Россия выступила в качестве третьего лица. В 1992 г. Российская Федерация 
признала юрисдикцию над бывшими советскими вооруженными силами, включая те, которые были размещены на территории Латвии. Заявительницы и родители первой заявительницы были включены в регистр жителей Латвии как «бывшие граждане СССР». В то время никто из них не был гражданином какой-либо страны. Власти Латвии посчитали незаконным их дальнейшее пребывание на территории страны. Заявители утверждали, что их высылка нарушила статью 3 Протокола №4, учитывая, что Латвия была их родиной и что до 1991 г. они состояли в гражданстве Латвийской Советской Социалистической Республики.

Латвия заявила, что понятие «гражданство» по смыслу статьи 3 Протокола №4 регулируется исключительно нормами национального права и что соответственно государство правомочно определять, является ли лицо гражданином этого государства или нет. Тот факт, что заявители были гражданами Латвийской ССР до распада СССР, не имеет значения, так как заявители никогда не были гражданами независимой Латвии. Поэтому власти Латвии считают эти требования несовместимыми с Конвенцией. В своем Решении о приемлемости жалобы ${ }^{20}$ ЕСПЧ отметил, что статья 3 Протокола №4 гарантирует абсолютную и безусловную свободу граждан от высылки. Однако Суд считает, что для целей статьи 3 Протокола №4 гражданство заявителей должно быть определено в принципе со ссылкой на национальное законодательство. Право на гражданство, идентичное праву, закрепленному в статье 15 Всеобщей декларации прав человека, не гарантировано Конвенцией или Протоколами к ней, хотя произвольный отказ в гражданстве, при определенных условиях, может рассматриваться как вмешательство в права, гарантированные статьей 8 Конвенции (см., mutatis mutandis, дело «Карасев и семья против Финляндии» (“Karassev and Family v. Finland”) №31414/96, 12 января 1999 года, ECHR 1999-II).

Законодательство Латвии не разделяет понятия «гражданство» и «национальность», и не вызывает сомнений тот факт, что первый и третий заявители не были гражданами Латвии после 27 июня 1997 года, то есть после даты, когда Конвенция вступила в силу для Латвии. Также нет никаких указаний на то, что первому и третьему заявителям необоснованно отказали в латвийском гражданстве. ЕСПЧ пришел к выводу о неприемлемости данной жалобы в связи с отсутствием у Суда юрисдикции ratione materiae, поскольку рассматриваемое положение Протокола касается только граждан высылающего государства. 
Что касается пункта 2 Статьи 3 Протокола №4, то закрепленное в нем право на возвращение в страну своего гражданства не может считаться абсолютным правом на пребывание на его территории согласно Пояснительному докладу ${ }^{21}$. Например, преступник, который был экстрадирован государством своего гражданства, затем сбежал из тюрьмы в другом государстве, не будет иметь безусловного права сбежать в страну своего гражданства. Также как и солдат, который служит на территории государства, не являющимся государством его гражданства, не будет иметь право на возвращение в свою страну с целью там остаться.

\section{International Protection of the Rights of Forced Migrants in Judgments of the European Court of Human Rights (Part I) (Summary)}

\section{Dmitriy V. Ivanov*}

The article highlights the role of the European Court of Human Rights in international protection of the rights of migrants and expands on the practice of the Court regarding various rights and freedoms granted by the European convention on human rights and its Protocols (1950).

In the first part of the article a specific attention is drawn to the ECHR practice of considering cases of deportation and extradition, including those concerning the Russian Federation.

Keywords: human rights; European Court of Human Rights; European convention on human rights; rights of migrants; deportation; extradition.

\footnotetext{
* Dmitriy V. Ivanov - Ph.D. in Law, professor of the International law department, MGIMOUniversity MFA Russia. prof.ivanovdv@gmail.com.
} 
${ }^{1}$ Лобов М. Вопросы применения Европейской конвенции по правам человека. Гарантии имущественных прав. Защита прав беженцев. Контроль за исполнением решений Европейского суда. М.: «Р.Валент», 2001. URL: http://www.memo.ru/hr/refugees/sem9rus/ index.htm (дата обращения: 28.10.2012).

${ }^{2}$ Chahal v. the United Kingdom, 15 November 1996, Reports of Judgments and Decisions 1996V.

${ }^{3}$ Lambert H. The European Convention on Human Rights and the Protection of Refugees: Limits and Opportunities UNHCR, 2005. Refugee Survey Quarterly, Vol. 24, Issue. P. 39.

${ }^{4}$ Nasrulloyev v. Russia, no. 656/06, § 71, 11 October 2007.

${ }^{5}$ Gonzalez v. Spain (dec.), no. 43544/98, 29 June 1999.

${ }^{6}$ Gerry A. Article 5: right to liberty and security//Human Rights Practice. 5.041.

${ }^{7}$ Al-Nashif v. Bulgaria, no. 50963/99, 20 June 2002.

${ }^{8}$ Slivenko v. Latvia [GC], no. 48321/99, § 149, ECHR 2003X.

${ }^{9}$ M. and Others v. Bulgaria, no. 41416/08, 26 July 2011// Извлечение в Бюллетене Европейского Суда по правам человека Российское издание. N 1/2012. Доступ из справ.прав.системы «Гарант».

${ }^{10}$ Amuur v. France, 25 June 1996, Reports of Judgments and Decisions 1996III/ Анализ: Чернышева О. Руководство Совета Европы по применению концепции третьей безопасной страны правовое и социальное положение вынужденных мигрантов в России. URL: http://www.memo.ru/hr/refugees/sem12/chapter8.htm (дата обращения: 20.10.2012).

${ }^{11}$ Nolan and K. v. Russia, no. 2512/04, $\S \S 90-100,12$ February 2009.

${ }^{12}$ Nolan and K. v. Russia, no. 2512/04, $\S \S 90-100,12$ February 2009.

${ }^{13}$ Čonka v. Belgium, no. 51564/99, § $35-46$, ECHR 2002I.

${ }^{14}$ Dzhurayev v. Russia, no. 38124/07, §§38, 64 - 77, 17 December 2009

${ }^{15}$ Abdulkhakov v. Russia, no. 14743/11, § 172 - 176, 2 October 2012.

${ }^{16}$ Olsson v. Sweden, judgment of 24 March 1988, Series A no. 130, pp. 27-28, § 54, и Sommerfeld v. Germany [GC], no. 31871/96, § 86, ECHR 2003-VIII.

${ }^{17}$ U. and S. v. Germany, no. 11825/85, Commission decision of 1 December 1986; Paramanathan v. Germany, no. 12068/86, Commission decision of 1 December 1986, Decisions and Reports (DR) 51, p. 240.

${ }^{18}$ Omwenyeke v. Germany (dec.), No.44294/04, 20 November 2007.

${ }^{19}$ Explanatory Report. Protocol No. 4 to the Convention for the Protection of Human Rights and Fundamental Freedoms, securing certain rights and freedoms other than those already included in the Convention and in the first Protocol thereto. URL: http://conventions.coe. int/Treaty/en/reports/html/046.htm (access date: 25.02 .2013 ).

${ }^{20}$ Slivenko v. Latvia [GC] (dec.), no. 48321/99, §§ 77 - 79, ECHR 2002-II.

${ }^{21}$ Explanatory Report. Protocol No. 4 to the Convention for the Protection of Human Rights and Fundamental Freedoms, securing certain rights and freedoms other than those already included in the Convention and in the first Protocol thereto. URL: http://conventions.coe. int/Treaty/en/reports/html/046.htm (access date: 25.02 .2013 ). 